\title{
Arginase inhibition by rhaponticin increases L-arginine concentration that contributes to $\mathrm{Ca}^{2+}$-dependent eNOS activation
}

\author{
Bon-Hyeock Koo ${ }^{1}$, Jonghoon Lee ${ }^{2}$, Younghyun Jin ${ }^{2}$, Hyun Kyo Lim ${ }^{2, *}$ E Sungwoo Ryoo ${ }^{1, *}$ \\ ${ }^{1}$ Department of Biological Sciences, Kangwon National University, Chuncheon 24341, ${ }^{2}$ Department of Anesthesiology and Pain Medicine, \\ Yonsei University Wonju College of Medicine, Wonju 26426, Korea
}

\begin{abstract}
Although arginase primarily participates in the last reaction of the urea cycle, we have previously demonstrated that arginase II is an important cytosolic calcium regulator through spermine production in a p32-dependent manner. Here, we demonstrated that rhaponticin (RPT) is a novel medicinal-plant arginase inhibitor and investigated its mechanism of action on $\mathrm{Ca}^{2+}$-dependent endothelial nitric oxide synthase (eNOS) activation. RPT was uncompetitively inhibited for both arginases I and II prepared from mouse liver and kidney. It also inhibited arginase activity in both aorta and human umbilical vein endothelial cells (HUVECs). Using both microscope and FACS analyses, RPT treatments induced increases in cytosolic $\mathrm{Ca}^{2+}$ levels using Fluo-4 AM as a calcium indicator. Increased cytosolic $\mathrm{Ca}^{2+}$ elicited the phosphorylations of both CaMKII and eNOS Ser1177 in a time-dependent manner. RPT incubations also increased intracellular L-arginine (L-Arg) levels and activated the CaMKII/AMPK/Akt/eNOS signaling cascade in HUVECs. Treatment of L-Arg and $\mathrm{ABH}$, arginase inhibitor, increased intracellular $\mathrm{Ca}^{2+}$ concentrations and activated CaMKII-dependent eNOS activation in ECs of WT mice, but, the effects were not observed in ECs of inositol triphosphate receptor type 1 knockout $\left(\right.$ IP3R1 $^{-1-}$ ) mice. In the aortic endothelium of WT mice, RPT also augmented nitric oxide (NO) production and attenuated reactive oxygen species (ROS) generation. In a vascular tension assay using RPT-treated aortic tissue, cumulative vasorelaxant responses to acetylcholine (Ach) were enhanced, and phenylephrine (PE)-dependent vasoconstrictive responses were retarded, although sodium nitroprusside and $\mathrm{KCl}$ responses were not different. In this study, we present a novel mechanism for RPT,
\end{abstract}

*Corresponding authors. Sungwoo Ryoo, Tel: +82-33-250-8534; Fax: +82-33-251-3990; E-mail: ryoosw08@kangwon.ac.kr; Hyun Kyo Lim, Tel: +82-33-741-1536; Fax: +82-33-742-8198; E-mail: hyunkyolim@ yonsei.ac.kr

https://doi.org/10.5483/BMBRep.2021.54.10.053

Received 12 April 2021, Revised 2 May 2021, Accepted 17 May 2021

Keywords: Arginase, $\mathrm{Ca}^{2+}$, eNOS, L-Arginine, Rhaponticin as an arginase inhibitor, to increase cytosolic $\mathrm{Ca}^{2+}$ concentration in a L-Arg-dependent manner and enhance endothelial function through eNOS activation. [BMB Reports 2021; 54(10): 516-521]

\section{INTRODUCTION}

For ammonia detoxification, arginase acts in the last reaction of the urea cycle by catalyzing the lysis of L-arginine (L-Arg) to L-ornithine and urea. The production of L-ornithine, a polyamine-synthesis precursor, has been shown to be important for inducing both cell proliferation and differentiation $(1,2)$. Arginase II (ArgII), the extra-hepatic isoform, is targeted to mitochondria and is mainly expressed in aortic endothelial cells (AECs) in both humans and mice. The upregulation of Argll upregulation has been demonstrated in vascular disorders related to ageing $(3)$, ischemia/reperfusion $(4,5)$, hypertension $(6,7)$, balloon injury (8), and atherosclerosis (9). This upregulation may also contribute to decreased nitric oxide (NO) bioavailability $(3,9,10)$. In the reciprocally regulated mechanism of Argll-dependent NO production, Argll translocation to the cytosol causes a reduction in L-Arg and inactivation of endothelial NO synthase (eNOS). This has been demonstrated in studies with L-Arg as the common substrate for both Argll and eNOS (11). We have previously reported that Argll also regulates $\mathrm{Ca}^{2+}$ translocation from the cytosol to mitochondria and the cytosolic $\mathrm{Ca}^{2+}$ concentration $\left(\left[\mathrm{Ca}^{2+}\right] \mathrm{c}\right)$ in p32-dependent manner (10). Accordingly, Argll-dependent $\mathrm{Ca}^{2+}$ regulation has also been shown to participate in the activation of the CaMKII/ AMPK/Akt/eNOS Ser1177 phosphorylation signaling cascade (12). These findings suggest that Argll plays a crucial role in intracellular $\mathrm{Ca}^{2+}$ regulation and its signaling cascade, although Argll primarily participated in the urea cycle to detoxification of ammonia. Therefore, Argll downregulation contributed to activation of $\mathrm{Ca}^{2+}$ signaling cascade in physiological conditions such as cardiovascular, neuronal, muscular system.

For the maintenance of vascular homeostasis, $\mathrm{NO}$ generated from eNOS plays important roles in the modulation of vascular tone and in the proliferation and migration of vascular smooth muscle cells. Although its activity can be regulated by a variety

ISSN: 1976-670X (electronic edition)

Copyright (C) 2021 by the The Korean Society for Biochemistry and Molecular Biology

c) This is an open-access article distributed under the terms of the Creative Commons Attribution Non-Commercial License (http://creativecommons.org/licenses/by-nc/4.0) which permits unrestricted non-commercial use, distribution, and reproduction in any medium, provided the original work is properly cited. 
of factors, $\left[\mathrm{Ca}^{2+}\right] \mathrm{c}$ is known to be an important regulator of eNOS activity. The activation of calmodulin $\left(\mathrm{Ca}^{2+} / \mathrm{CaM}\right)$ by increased $\left[\mathrm{Ca}^{2+}\right] \mathrm{c}$ promotes the alignment of the reductase and oxygenase domains, and prevents the phosphorylation of eNOS Thr495 through direct binding to the CaM-binding domain in eNOS, leading to efficient $\mathrm{NO}$ synthesis. $\mathrm{Ca}^{2+} / \mathrm{CaM}$ also induces $\mathrm{Ca}^{2+} / \mathrm{CaM}$-dependent protein kinase II (CaMKII) activation, which phosphorylates eNOS Ser1177 to enhance NO production $(13,14)$.

The perennial herb Rheum undulatum $\mathrm{L}$ has traditionally been used as a purgative, laxative, anti-inflammatory, and antiblood stagnation agent in eastern Asia (including Korea). Among the useful components isolated from this herb, rhaponticin (RPT; 3'5-dihydroxy-4'-methoxystilbene 3-O- $\beta$-D-glucopyranoside, Fig. $1 \mathrm{~A}$ ) has been shown to have beneficial effects, including anti-allergic, anti-diabetic, and anti-thrombotic activities $(15,16)$. Furthermore, RPT has been shown to effectively alleviate colitis, pulmonary fibrosis, and liver steatosis (17-19). However, RPT's influence on regulating vascular function, its molecular target, and mechanism of action, have not yet been identified.

In the present study, we identified RPT as an arginase inhibitor and demonstrated a molecular mechanism associated with $\mathrm{Ca}^{2+}$-dependent eNOS activation through increased L-Arg levels. In addition, mouse vascular-function assay was used to demonstrate that RPT increased NO production and reduced ROS generation in isolated aortic endothelium.

\section{RESULTS}

RPT inhibited arginase activity in an uncompetitive manner RPT (Fig. 1A) inhibited arginase I (liver lysate, Fig. 1B) and II activity (kidney lysate, Fig. 1C) in a concentration-dependent manner. The residual activities of arginase I and II with $40 \mu \mathrm{M}$
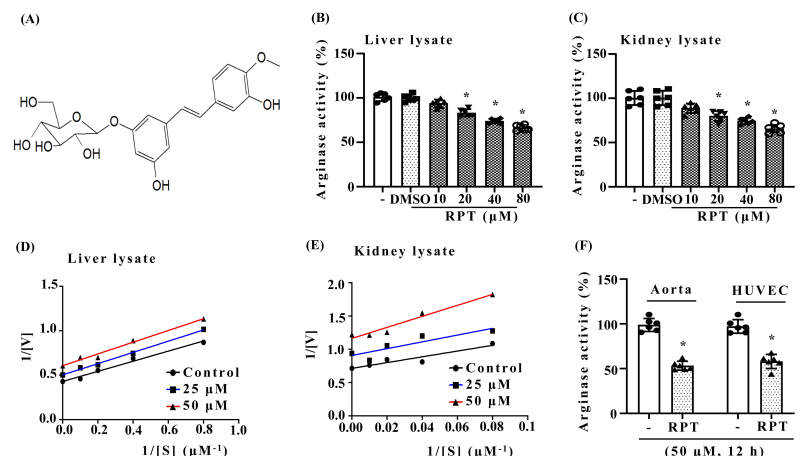

Fig. 1. Rhaponticin (RPT) inhibited arginase activity in an uncompetitive manner. (A) Structure of RPT. RPT inhibited arginase activity in liver (B) and in kidney $(\mathrm{C})$ lysates in a dose-dependent manner. Lineweaver-Burk plots showed RPT as uncompetitive inhibitor of arginase I and II prepared from liver (D) and kidney (E) lysates. (F) RPT treatment $(50 \mu \mathrm{M})$ of aortic vessels and HUVECs for 12 $\mathrm{h}$ decreased arginase activity. $\mathrm{n}=3$ experiments. * vs. untreated control, $\mathrm{P}<0.05$.
RPT were $74.0 \pm 2.73 \%$ and $74.4 \pm 3.57 \%$, respectively. To test the biochemical properties of RPT on arginase inhibition, we performed Lineweaver-Burk plots at different RPT concentrations $(25$ and $50 \mu \mathrm{M})$. The RPT data showed the same slopes, but different y-intercepts for arginase I (Fig. 1D) and II (Fig. 1E). We, therefore, defined RPT as an uncompetitive inhibitor against arginase I and II. In addition, RPT treatments in isolated aortas and HUVECs decreased arginase activity (Fig. 1F). These data indicated that RPT inhibited arginase activity from molecule to tissue level.

\section{RPT increased $\left[\mathrm{Ca}^{2+}\right] \mathrm{c}$, resulting in eNOS Ser1177 phosphorylation}

We previously reported that arginase inhibition activated eNOS in a $\mathrm{Ca}^{2+}$-dependent manner (10). So, we first measured $\left[\mathrm{Ca}^{2+}\right]$ c. RPT incubation with HUVECs significantly increased $\left[\mathrm{Ca}^{2+}\right] \mathrm{c}$ examined for Fluo-4 signal both under a microscope (Fig. 2A, untreated vs. RPT, $10.04 \pm 2.07$ vs. $16.15 \pm 2.45$ fluorescence intensity, $\mathrm{P}<0.05$ ) and using FACS (Fig. 2B, untreated vs. RPT, $1.01 \pm 0.26$ vs. $1.68 \pm 0.11$ fluorescence intensity, $\mathrm{P}<$ 0.05). The increased $\left[\mathrm{Ca}^{2+}\right] \mathrm{c}$ by RPT incubation caused eNOS activation through the signaling cascade of CaMKII/AMPK/ Akt/eNOS Ser1177 phosphorylation (Fig. 2C, * vs. untreated, $\mathrm{P}<0.05)$, but prevented eNOS Thr495 phosphorylation.

(A)
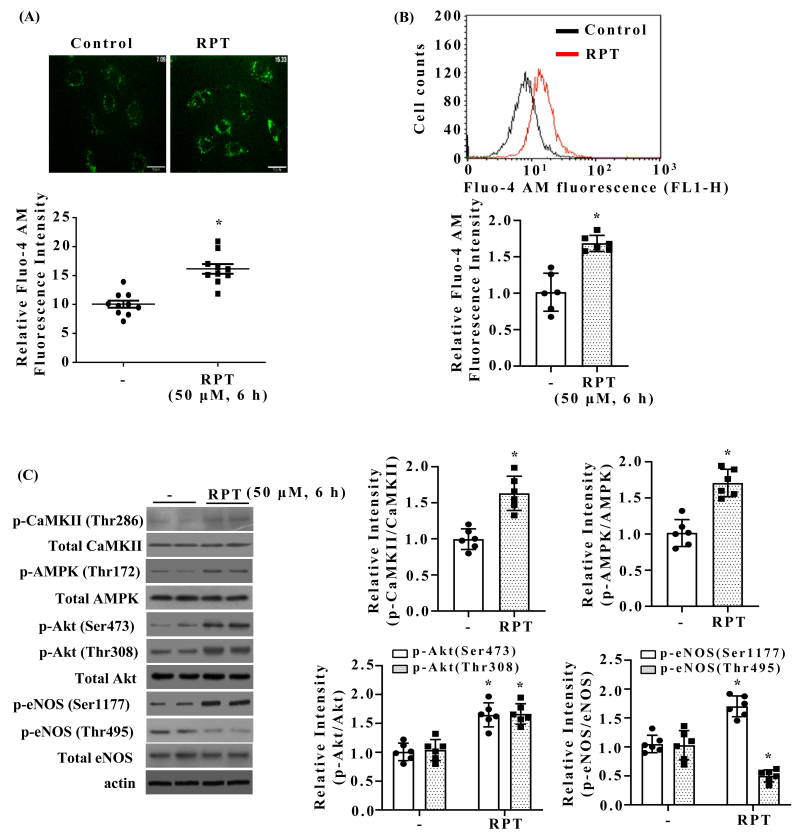

Fig. 2. Arginase inhibition by RPT increased $\left[\mathrm{Ca}^{2+}\right] \mathrm{c}$ and induced eNOS Ser1177 phosphorylation in a $\mathrm{Ca}^{2+}$-dependent manner. RPT incubation $(50 \mu \mathrm{M})$ for $6 \mathrm{~h}$ elevated $\left[\mathrm{Ca}^{2+}\right] \mathrm{c}$ in HUVECs assessed using Fluo-4 by microscope (A) and by FACS (B). (C) RPT treatment activated the CaMKII/AMPK/Akt/eNOS Ser 1177 phosphorylation signaling cascade. $\mathrm{n}=3$ experiments. ${ }^{*}$ vs. untreated control, $\mathrm{P}<0.05$. 


\section{Increased L-Arg levels caused by RPT treatment induced $\mathrm{Ca}^{2+}$-dependent eNOS phosphorylation}

We next determined how arginase inhibition could increase $\left[\mathrm{Ca}^{2+}\right] \mathrm{c}$ by measuring L-Arg concentration using HPLC. Intracellular L-Arg concentrations were increased in RPT-treated HUVECs (Fig. 3A, untreated vs. L-Arg, $0.36 \pm 0.04$ vs. $0.50 \pm$ $0.03 \mathrm{mM}, \mathrm{P}<0.01)$. HUVECs incubation with L-Arg enhanced their $\left[\mathrm{Ca}^{2+}\right] \mathrm{C}$ using both microscope assay (Fig. 3B, untreated vs. L-Arg, $9.52 \pm 2.43$ vs. $18.79 \pm 1.26$ fluorescence intensity, $\mathrm{P}<0.01$ ) and a FACS assay (Fig. 3C, untreated vs. L-Arg, $1.00 \pm 0.15$ vs. $1.63 \pm 0.11$ relative fluorescence intensity, $P<$ 0.01). Consistently, L-Arg treatment induced eNOS activation through the CaMKII/AMPK/Akt/eNOS phosphorylation pathway (Fig. 3D, * vs. untreated, $\mathrm{P}<0.05$ ) and dephosphorylation of eNOS Thr495. To confirm the L-Arg effect, we further tested that $\mathrm{L}-\mathrm{Arg}$ and $\mathrm{ABH}$, arginase inhibitor, have the influence the $\mathrm{Ca}^{2+}$ levels and the signaling cascade in ECs of inositol triphosphate receptor type 1 knockout (IP3R ${ }^{-1-}$ ) mice. In intracellular $\mathrm{Ca}^{2+}$ measurement using FACS (Fig. 3E) and microscope (Fig. 3F), L-Arg and ABH treatments increased $\mathrm{Ca}^{2+}$ levels in ECs of WT mice (Fig. 3E, untreated vs. L-Arg, $1.00 \pm$ 0.19 vs. $1.66 \pm 0.13$, untreated vs. $\mathrm{ABH}, 1.00 \pm 0.19$ vs. $1.64 \pm$
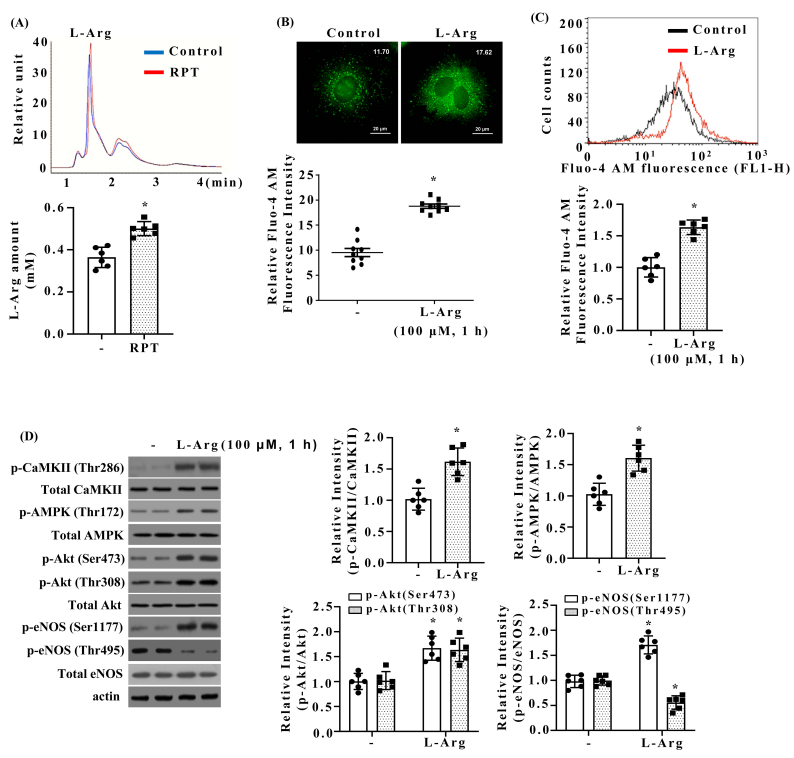

Fig. 3. L-Arg increased $\left[\mathrm{Ca}^{2+}\right] \mathrm{c}$, resulting in eNOS Ser1177 phosphorylation. (A) HPLC analysis showing that RPT incubation increased the intracellular concentration of L-Arg. The microscope (B) and FACS (C) assessments demonstrated that L-Arg treatment increased $\left[\mathrm{Ca}^{2+}\right] \mathrm{C}$. (D) L-Arg incubation also activated the CaMKII/AMPK/ Akt/eNOS Ser 1177 signaling pathway of. $\mathrm{n}=3$ experiments, $\mathrm{P}<0.05$. In L-Argand $\mathrm{ABH}$-treated ECS from WT and IP3R1 KO mice, cytosolic $\mathrm{Ca}^{2+}$ levels were measured using FACS $(\mathrm{E})$ and microscope $(\mathrm{F}) . \mathrm{n}=3$ experiments. ${ }^{*}$ vs. untreated control, $\mathrm{P}<0.05$. ns, not significant. (G) L-Arg and $\mathrm{ABH}$ induced CaMKII and eNOS activations in WT mice, but not in IP3R1 KO mice. $\mathrm{n}=3$ experiments. ${ }^{*}$ vs. untreated control, $\mathrm{P}<0.05$; \# vs. untreated control of WT mice, $\mathrm{P}<0.05$.
0.13 relative fluorescence intensity, $\mathrm{P}<0.05$; Fig. 3F, untreated vs. L-Arg, $9.37 \pm 1.96$ vs. $16.91 \pm 2.99$, untreated vs. $\mathrm{ABH}$, $9.37 \pm 1.96$ vs. $18.80 \pm 2.36$ relative fluorescence intensity, $\mathrm{P}<0.05)$, but, the effect was not observed in ECs of IP3R ${ }^{-}$ mice. CaMKII-dependent eNOS activation was elicited by L-Arg and $\mathrm{ABH}$ in WT mice, but, the signaling cascade was significantly blunted in IP3R $1^{-1-}$ mice (Fig. 3G). Therefore, these results indicated that increased intracellular L-Arg level, L-Arg supplement and arginase inhibition, induced $\mathrm{Ca}^{2+}$-dependent eNOS activation through facilitated IP3R1-dependent $\mathrm{Ca}^{2+}$ release.

RPT enhanced vascular function in a NO-dependent manner In the endothelium of isolated aortas, incubation with RPT enhanced NO production (Fig. 4A, untreated vs. RPT, $0.72 \pm$ 0.06 vs. $1.15 \pm 0.12$ intensity/s, $P<0.01 ;$ L-NAME $=0.07 \pm$ 0.03 intensity/s) and attenuated ROS generation (Fig. 4B, untreated vs. RPT, $0.29 \pm 0.05$ vs. $0.11 \pm 0.02$ intensity/s, $\mathrm{P}<$ $0.01 ; \mathrm{MnTBAP}=0.006 \pm 0.005$ intensity/s). Using a vasculartension assay, RPT induced augmentation of Ach-dependent vasorelaxant responses (Fig. 4C, $\operatorname{logEC} 50$; untreated vs. RPT, $-6.85 \pm 0.07$ vs. $-7.09 \pm 0.05 \mathrm{M}, \mathrm{P}<0.05$; Emax, untreated vs. RPT, $83.53 \pm 2.29 \%$ vs. $98.37 \pm 1.70 \%, \mathrm{P}<0.01)$ and reduced PE-dependent vasoconstrictive responses (Fig. 4D, logEC50; untreated vs. RPT, $-6.63 \pm 0.05$ vs. $-6.87 \pm 0.10 \mathrm{M}, \mathrm{P}<$ 0.05; Emax, untreated vs. RPT, $243.8 \pm 6.0 \%$ vs. $160.2 \pm$ $6.6 \%, \mathrm{P}<0.01$ ). However, sodium nitroprusside (SNP; an endothelium-independent relaxant as a $\mathrm{NO}$ donor, Fig. $4 \mathrm{E}$ ) and $\mathrm{KCl}$ responses (endothelium-independent vessel constrictor, Fig. 4F) were not different between groups. These results, RPT

(E)
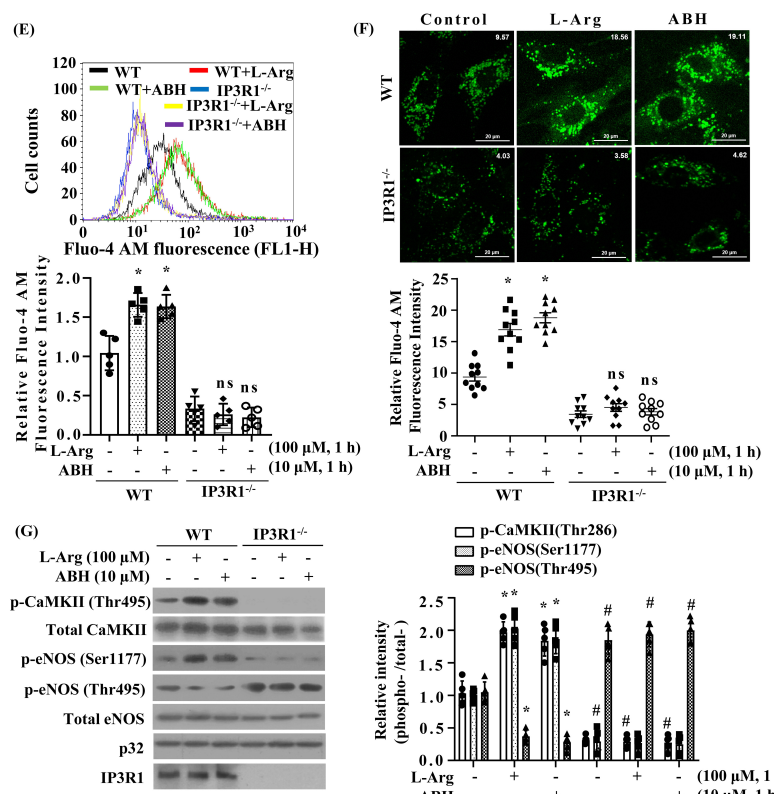

口-CaMKII(Thr286) 마 p-eNOS(Ser1177)

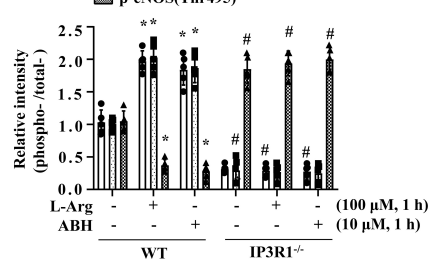

Fig. 3. Continued. 

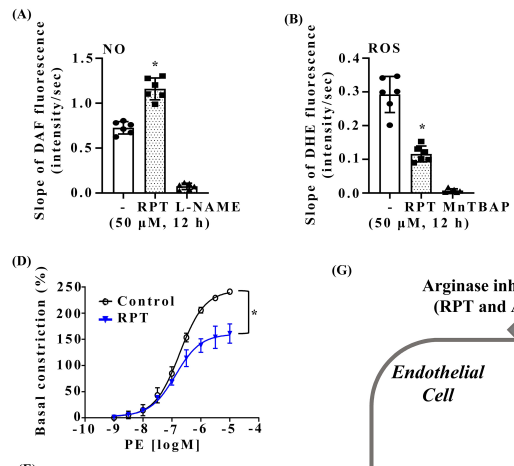

(E)

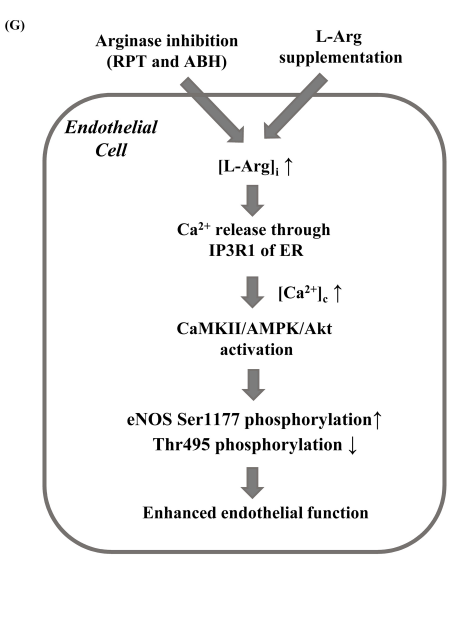

Fig. 4. RPT enhanced NO production and Ach-induced vasorelaxation. NO production in the aortic endothelium of WT mice was enhanced after incubation with RPT (A) and ROS generation was prevented (B). L-NAME and MnTBAP were used as negative controls. $\mathrm{n}=6$ from three mice. Isolated aortic vessels incubated with RPT showed enhanced Ach-dependent vasorelaxation responses (C) and retarded PE-dependent vasoconstrictive responses (D). The SNP (E) and KCl (F) responses were not different between groups. * vs. untreated control, $\mathrm{P}<0.05 . \mathrm{n}=9$ from three mice. (G) Schematic representation. Increased $\mathrm{L}$-arginine levels induced $\mathrm{Ca}^{2+}$-dependent eNOS activation.

incubation enhanced NO-dependent vasorelaxtion, confirmed again in the tissue level.

\section{DISCUSSION}

The present results demonstrate that RPT inhibited both arginase I and II activities uncompetitively, induced increases in cytosolic $\mathrm{Ca}^{2+}$ levels, and increased the intracellular concentration of L-Arg. This increase in cytosolic $\mathrm{Ca}^{2+}$ induced by RPT elicited the activation of the CaMKII/AMPK/Akt/eNOS signaling cascade; a result mimicked by incubation with L-Arg in IP3R1dependent manner. In the endothelium of WT mouse aortas, RPT augmented NO production and attenuated ROS generation. Using a vascular-tension assay consisting of RPT-treated aortic tissue, the cumulative responses to Ach (as a vasorelaxant) were enhanced and PE-dependent vasoconstrictive responses were retarded.

Arginase inhibition increased the concentration of cytosolic $\mathrm{Ca}^{2+}$ both here and in our previous study that was not due to an extracellular $\mathrm{Ca}^{2+}$ source (10). Accordingly, it is known that cellular $\mathrm{Ca}^{2+}$ homeostasis can be regulated both by the endoplasmic reticulum and by mitochondria. In our previous study, we demonstrated that arginase II played an important role in the regulation of $\mathrm{Ca}^{2+}$ concentration between mitochondria and the cytosol in a p32-dependent manner (10). In addition, both arginase inhibition and knockdown has been shown to increase cytosolic $\mathrm{Ca}^{2+}$ levels that resulted in eNOS activation through CaMKII/AMPK/Akt/eNOS Ser1177 phosphorylation (12), and this signaling cascade was not dependent on $\mathrm{NO}$ as shown in eNOS ${ }^{-1-}$ mice (10). Therefore, increased L-Arg levels due to downregulation of arginase may be involved in $\mathrm{Ca}^{2+}$. dependent eNOS activation through IP3R1.

The concept of an L-Arg paradox exists in mammal whereby $\mathrm{L}-\mathrm{Arg}$ concentrations far exceed the $\mathrm{Km}$ value of eNOS. As a consequence of this, additional L-Arg should not augment NO production. However, increasing plasma concentrations of L-Arg in vivo have repeatedly been reported to augment NO generation. The three L-Arg pools existing within cells are: (1) a pool that is easily exchangeable by extracellular L-Arg (pool I), transported by a cationic transporter (CAT-1), and can be exhausted by exchanging the pool with the cationic amino acid such as L-lysine; (2) the second pool that is non-exchangeable with extracellular L-Arg (pool II) and that cannot be exhausted by L-lysine; and (3) an extracellular L-Arg pool (pool III) exists in endothelial cells and mitochondria in which arginase II controls NO production via a non-exchangeable L-Arg pool (20). According to latest research, pool II (non-exchangeable L-Arg) has two microdomains in cytosol. The main function of the pool IIA microdomain seems to be the result of L-citrulline recycling and conversion to L-Arg by sequential reactions of argininosuccinate synthetase and argininosuccinate lyase that can be depleted by neutral amino acids such as histidine (21). The remaining microdomain (pool IIB) is mainly used by mitochondria and is composed of L-Arg resulting from protein lysis and cannot be exhausted by a neutral amino acid such as histidine. In the present study, we have shown that RPT is an arginase inhibitor, and that L-Arg supplementation augmented the $\mathrm{Ca}^{2+}$-dependent signaling cascade for eNOS activation. This effect may be attributed to both pool I and pool IIA increases in L-Arg levels.

We, therefore, believe that IP3R1 as a target molecules associated with $\mathrm{Ca}^{2+}$ release due to increased L-Arg concentrations may be clues for explaining the L-Arg paradox, although the present studies focused on a common substrate (L-Arg) bioavailability to explain the L-Arg paradox.

In conclusion, Argll inhibition with RPT or ABH and L-Arg supplementation increased cytosolic L-Arg level. Increased cytosolic $\mathrm{L}$-Arg could induced $\mathrm{Ca}^{2+}$ release through IP3R1 of ER and then activated CaMKII/AMPK/Akt/eNOS signaling cascade. The enhanced NO production improved endothelial function (Fig. 4G).

\section{MATERIALS AND METHODS}

\section{Materials}

Rhaponticin (RPT, Cat. No. 155-58-8), was purchased from SigmaAldrich (St Louis, MO). N $N^{G}$-nitro-L-arginine methyl ester (L-NAME, 
Cat. No. 15190-44-0), manganese (III) tetrakis (4-benzoic acid) porphyrin chloride (MnTBAP, Cat. No. 55266-18-7), and 2(S)amino-6-boronohexanoic acid (ABH, Cat. No. 194656-75-2) were purchased from Calbiochem (Darmstadt, Germany). Antisera against eNOS (Cat. No. 610297) and phospho-eNOS (Ser1177, Cat. No. 612392 and Thr495, Cat. No. 612707) were obtained from BD Biosciences (San Jose, CA). phospho-CaMKII (Thr286, Cat. No. \#12716), CaMKII (Cat. No. \#3362), phospho-Akt (Ser473, Cat. No. \#9271 and Thr308, Cat. No. \#9275), Akt (Cat. No. \#9272), phospho-AMPK $\alpha$ (Thr172, Cat No. \#2531), AMPK $\alpha$ (Cat No. \#2532) and pan-actin (Cat. No. \#4968) were obtained from Cell Signaling Technology (Beverly, MA).

\section{Cell culture and animals}

HUVECs were purchased from Cascade Biologics (Cat. No. C0035C, Portland, OR) and were maintained according to the supplier's instructions. Ten-week old male C57BL6J WT mice were fed a normal diet (ND; Cat. No. 38057133-27, Nara Biotech Co. Seoul, Korea). IP3R $1^{-1-}$ mice was generated from mating of IP $3 R 1^{+1-}$ mice. Isolation of ECs from mice aortas was conducted using collagenase type 2 incubation. All mice were maintained at the Kangwon National University Animal Services Facility. This study was approved in accordance with the Guide for the Care and Use of Laboratory Animals (Approval No. KIACUC-09-0134). This investigation conformed to the principles outlined in the Declaration of Helsinki.

\section{Arginase activity measurements}

After mouse kidneys, livers, and aortas were isolated, enzyme extracts were prepared. Tissues were homogenized for $2 \mathrm{~min}$, sonicated for $25 \mathrm{~s}$, centrifuged $12,000 \mathrm{rpm}$ at $4^{\circ} \mathrm{C}$ for $20 \mathrm{~min}$, and the supernatants used as enzyme extracts. For aorta samples, $1.5 \mathrm{~cm}$ tissue samples were first cut into $2 \mathrm{~mm}$ pieces, pulverized by homogenization for $30 \mathrm{~min}$, centrifuged 12,000 rpm at $4^{\circ} \mathrm{C}$ for $20 \mathrm{~min}$ ) and then supernatant was used as the enzyme extracts. The enzyme extracts and RPT were then reacted $\left(37^{\circ} \mathrm{C}\right.$, $1 \mathrm{~h})$ at the indicated concentrations using Tris- $\mathrm{HCl}(\mathrm{pH} 7.5)$ and L-Arg $(0.1 \mathrm{M})$. Enzyme reactions were stopped by adding acidic solution $\left(10 \% \mathrm{H}_{2} \mathrm{SO}_{4}, 30 \% \mathrm{H}_{2} \mathrm{PO}_{4}\right.$ in distilled water) and $9 \% \alpha$-isonitrosopropiophenone in ethanol (Sigma-Aldrich). The absorbance of reaction solution was measured at $550 \mathrm{~nm}$.

\section{High performance liquid chromatography}

After HUVEC lysis, samples were centrifuged $12,000 \mathrm{rpm}$ at $4^{\circ} \mathrm{C}$ for $20 \mathrm{~min}$ and the supernatants removed. Methanol (100 $\mu$ l) was added, and the mixtures sonicated five times. After centrifugation $12,000 \mathrm{rpm}$ at $4^{\circ} \mathrm{C}$ for $20 \mathrm{~min}$, the supernatants were collected. Then, each supernatant was mixed 1:1 with OPT solution (phthaldialdehyde $5.4 \mathrm{mg} / \mathrm{ml}$ in $0.5 \mathrm{M}$ borate buffer, $\mathrm{pH} 8.4,0.4 \% \beta$-mercaptoethanol) and reacted for 1 minute to obtain $50 \mu \mathrm{l}$ for the column $(4.6 \times 150 \mathrm{~mm}, 5 \mu \mathrm{m}$, Eclipe XDB-C18). The mobile phase was degassed with $0.1 \mathrm{M}$ phosphate buffer $\left(0.2 \mathrm{M} \mathrm{Na}_{2} \mathrm{HPO}_{4}, \mathrm{pH}\right.$ 4.0, DW: methanol = $1: 1$ ) at a flow rate of $1.5 \mathrm{ml} / \mathrm{min}$, and an excitation wavelength of $340 \mathrm{~nm}$ and an emission wavelength of $455 \mathrm{~nm}$ were used.

\section{Western-blot analysis}

SDS sample buffer $(62.5 \mathrm{mM}$ Tris-HCl pH 6.8, 2\% SDS, 10\% glycerol, $50 \mathrm{mM}$ DTT, $0.01 \%$ bromophenol blue) was added to each $60 \mathrm{~mm}$ culture dish and collected after mixing. After sample boiling $\left(105^{\circ} \mathrm{C}, 10 \mathrm{~min}\right)$ proteins were separated using SDS-PAGE and transferred to polyvinylidene fluoride (PVDF) membranes (Millipore, Burlington, MA, $4^{\circ} \mathrm{C}, 12 \mathrm{~h}$ ). Membranes were blocked with $5 \%$ skim milk, incubated with primary antibodies $\left(4^{\circ} \mathrm{C}, 12 \mathrm{~h}, 1: 1000\right.$ dilutions), and then incubated with secondary antibodies $\left(24^{\circ} \mathrm{C}, 2 \mathrm{~h}\right)$. The PVDF membranes were then activated for chemiluminescence and X-ray film was exposed. Band intensities were analyzed using $\mathrm{NIH}$ ImageJ software.

\section{$\left[\mathrm{Ca}^{2+}\right]_{\mathrm{c}}$ measurement using confocal microscopy and flow cytometry}

$\left[\mathrm{Ca}^{2+}\right]_{\mathrm{c}}$ was monitored using Fluo-4 AM (Cat. No. F14201, 100 nM, 1 h, Thermo Fisher Scientific, Waltham, MA) using an epifluorescence microscope (Olympus BX51) with appropriate filters (494 nm excitation, $506 \mathrm{~nm}$ emission). Intensity values were normalized to initial fluorescence values after background subtraction using Metamorph software (Molecular Probes, San Jose, CA). $\left[\mathrm{Ca}^{2+}\right]_{\mathrm{c}}$ was also determined using flow cytometry (FACSCalibur, BD Biosciences), and a fluorescence intensity value for each sample was determined using Cell Quest software (BD Biosciences).

\section{Measurements of NO and ROS}

Aortic rings isolated from 10-week old male WT mice were labeled for $\mathrm{NO}$ with $5 \mu \mathrm{M}$ 4-amino-5-methylamino-2',7'difluorofluorescein diacetate (Cat. No. 254109-22-3, DAF-FM DA) for $5 \mathrm{~min}$ at $30 \mathrm{sec}$ intervals. For the ROS measurements, the rings were labeled with $1 \mu \mathrm{M}$ dihydroethidine (Cat. No. 104821-25-2, DHE) for $5 \mathrm{~min}$ at $30 \mathrm{sec}$ intervals. Images were acquired using an Olympus BX51 epifluorescence microscope. Fluorescence intensity was measured using Metamorph software.

\section{Vascular tension assay}

Heparin was administered $1 \mathrm{~h}$ before mice were sacrificed. Mice were anesthetized using isoflurane, and each thoracic aorta (from the aortic root to the bifurcation of the iliac arteries) was rapidly isolated and cut into $1.5-\mathrm{mm}$ rings. The aortic rings were placed in ice-cold oxygenated Krebs-Ringer bicarbonate buffer $(118.3 \mathrm{mM} \mathrm{NaCl}, 4.7 \mathrm{mM} \mathrm{KCl}, 1.2 \mathrm{mM}$ $\mathrm{MgSO}_{4}, 1.6 \mathrm{mM} \mathrm{CaCl}_{2}, 25 \mathrm{mM} \mathrm{NaHCO}, 11.1 \mathrm{mM}$ glucose, $\mathrm{pH}$ 7.4) and suspended between two wire stirrups $(150 \mathrm{~mm})$ in a myograph (Multi Myograph System, DMT-620, Hinnerup, Denmark) containing $10 \mathrm{ml}$ of Krebs-Ringer $\left(95 \% \mathrm{O}_{2}-5 \% \mathrm{CO}_{2}\right.$, $\mathrm{pH} 7.4,37^{\circ} \mathrm{C}$ ). One stirrup was connected to a three-dimensional micromanipulator, and the other to a force transducer. The aortic rings were passively stretched at $10 \mathrm{~min}$ intervals in increments of $100 \mathrm{mg}$ to reach an optimal tone of $600 \mathrm{mg}$. 
After stretching to this $600 \mathrm{mg}$ value, its contractile response to $60 \mathrm{mM} \mathrm{KCl}$ was determined. This response to a maximal $\mathrm{KCl}$ does was used to normalize the responses to agonists across vessel rings. Dose-responses to the vasoconstrictor phenylephrine (PE; Cat. No. 59-42-7, $10^{-9}-10^{-5} \mathrm{M}$ ) were assessed, and responses to the vasodilators acetylcholine (Ach; Cat. No. 60-31-1, $10^{-9}-10^{-5} \mathrm{M}$ ) and sodium nitroprusside (SNP; Cat. No. 13755-38-9, $\left.10^{-10}-10^{-6} \mathrm{M}\right)$ were assessed after pre-constriction with PE $\left(10^{-5} \mathrm{M}\right)$.

\section{Statistical methods}

All experiments were performed using 3-4 biological replicates, with the specific number of replicates reported for each experiment. Student's t-tests and a two-way ANOVA were performed as appropriate (GraphPad Prism, GraphPad Software, San Diego, CA). Values were determined as mean \pm standard error of the mean (SE). Significance was assessed using $\mathrm{P}<0.05$ considered statistically significant.

\section{ACKNOWLEDGEMENTS}

This work was supported by the Basic Science Research Program of the National Research Foundation of Korea funded by the Ministry of Education, Science and Technology (2018 R1D1A1B07047959 to SR, 2019R1A6A3A1309450512 to BK). We thank to the Central Laboratory of Kangwon National University for technical assistance with the instruments.

\section{CONFLICTS OF INTEREST}

The authors have no conflicting interests.

\section{REFERENCES}

1. Ignarro LJ, Buga GM, Wei LH, Bauer PM, Wu G and del Soldato P (2001) Role of the arginine-nitric oxide pathway in the regulation of vascular smooth muscle cell proliferation. Proc Natl Acad Sci U S A 98, 4202-4208

2. Li H, Meininger CJ, Hawker JR Jr et al (2001) Regulatory role of arginase I and II in nitric oxide, polyamine, and proline syntheses in endothelial cells. Am J Physiol Endocrinol Metab 280, E75-82

3. Berkowitz DE, White R, Li D et al (2003) Arginase reciprocally regulates nitric oxide synthase activity and contributes to endothelial dysfunction in aging blood vessels. Circulation 108, 2000-2006

4. Hein TW, Zhang C, Wang W, Chang Cl, Thengchaisri N and Kuo $L$ (2003) Ischemia-reperfusion selectively impairs nitric oxide-mediated dilation in coronary arterioles: counteracting role of arginase. FASEB J 17, 2328-2330

5. Jung C, Gonon AT, Sjoquist PO, Lundberg JO and Pernow J (2010) Arginase inhibition mediates cardioprotection during ischaemia-reperfusion. Cardiovasc Res 85, 147-154

6. Johnson FK, Johnson RA, Peyton KJ and Durante W (2005) Arginase inhibition restores arteriolar endothelial function in Dahl rats with salt-induced hypertension. Am J Physiol Regul Integr Comp Physiol 288, R1057-1062
7. Zhang C, Hein TW, Wang W et al (2004) Upregulation of vascular arginase in hypertension decreases nitric oxidemediated dilation of coronary arterioles. Hypertension 44, 935-943

8. Peyton KJ, Ensenat D, Azam MA et al (2009) Arginase promotes neointima formation in rat injured carotid arteries. Arterioscler Thromb Vasc Biol 29, 488-494

9. Ryoo S, Gupta G, Benjo A et al (2008) Endothelial arginase II: a novel target for the treatment of atherosclerosis. Circ Res 102, 923-932

10. Koo BH, Hwang HM, Yi BG et al (2018) Arginase II contributes to the $\mathrm{Ca}(2+) /$ CaMKII/eNOS axis by regulating $\mathrm{Ca}(2+)$ concentration between the cytosol and mitochondria in a p32-dependent manner. J Am Heart Assoc 7, e009579

11. Pandey D, Bhunia A, Oh YJ et al (2014) OxLDL triggers retrograde translocation of arginase2 in aortic endothelial cells via ROCK and mitochondrial processing peptidase. Circ Res 115, 450-459

12. Koo BH, Won MH, Kim YM and Ryoo S (2020) p32-Dependent p38 MAPK activation by arginase II downregulation contributes to endothelial nitric oxide synthase activation in HUVECs. Cells 9, 392

13. Fleming I, Fisslthaler B, Dimmeler S, Kemp BE and Busse $\mathrm{R}$ (2001) Phosphorylation of $\mathrm{Thr}(495)$ regulates $\mathrm{Ca}(2+) /$ calmodulin-dependent endothelial nitric oxide synthase activity. Circ Res 88, E68-75

14. Salerno JC, Harris DE, Irizarry K et al (1997) An autoinhibitory control element defines calcium-regulated isoforms of nitric oxide synthase. J Biol Chem 272, 29769-29777

15. Matsuda H, Tewtrakul S, Morikawa T and Yoshikawa M (2004) Anti-allergic activity of stilbenes from Korean rhubarb (Rheum undulatum L.): structure requirements for inhibition of antigen-induced degranulation and their effects on the release of TNF-alpha and IL-4 in RBL-2H3 cells. Bioorg Med Chem 12, 4871-4876

16. Ko SK, Lee SM and Whang WK (1999) Anti-platelet aggregation activity of stilbene derivatives from Rheum undulatum. Arch Pharm Res 22, 401-403

17. Tao L, Cao J, Wei W, Xie H, Zhang $M$ and Zhang C (2017) Protective role of rhapontin in experimental pulmonary fibrosis in vitro and in vivo. Int Immunopharmacol 47, 38-46

18. Wei W, Wang L, Zhou K, Xie H, Zhang M and Zhang C (2017) Rhapontin ameliorates colonic epithelial dysfunction in experimental colitis through SIRT1 signaling. Int Immunopharmacol 42, 185-194

19. Chen J, Ma M, Lu Y, Wang L, Wu C and Duan H (2009) Rhaponticin from rhubarb rhizomes alleviates liver steatosis and improves blood glucose and lipid profiles in KK/Ay diabetic mice. Planta Med 75, 472-477

20. Topal G, Brunet A, Walch L, Boucher JL and DavidDufilho M (2006) Mitochondrial arginase II modulates nitric-oxide synthesis through nonfreely exchangeable L-arginine pools in human endothelial cells. J Pharmacol Exp Ther 318, 1368-1374

21. Solomonson LP, Flam BR, Pendleton LC, Goodwin BL and Eichler DC (2003) The caveolar nitric oxide synthase/arginine regeneration system for $\mathrm{NO}$ production in endothelial cells. J Exp Biol 206, 2083-2087 